Foldher Stüđe, welde vorher bercits in ber überjetzung mitgetheilt worben jinb, ijt bie Şinzufügung eines BSloffariums überflüffig gemorber.

Wenn unjer Şanbbud aud nidt als ber zweite Theil bes im borigen 3ahre in bemfelben Berlage von umo herauşgegebenen [nummehr Eereitz in 3. 2fuflage bet B. Reimer in Berlin erjdienenen] bentiden Rejebudfs auftritt, io jinbet es bod eine getwifje Ergänjung burd bajfelbe, infofern biejenigen Stï fe, bie iffrem 3nhalte nad

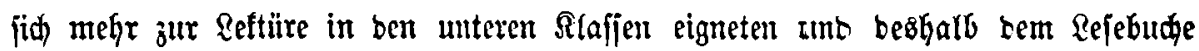

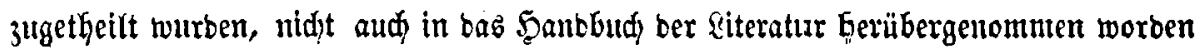
jine. So jinb bie Diditungen $\mathfrak{A}_{\mathrm{r}} \mathrm{bta}$, um nur cinize berühntere Didter her= borzuheben, im sejebuch ftärfer vertreten als in bem verliegenben Saanbbudfe; ebenfo

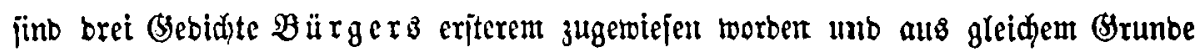
haben alch einige Didjtungen Bellerts, Sleims, (Soethes, Ferbers,

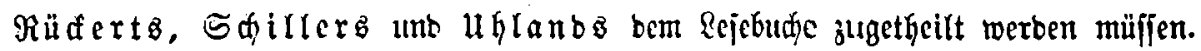

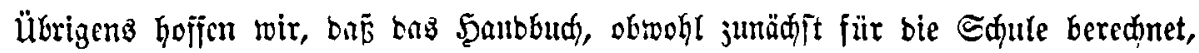
bod) aud auperfalb berielken sen ơrcunben Ler seutiden Qiteratur zu eingehenber Bejđäftigung mit ben હdjäten terjelten gecigneten Etcij tarbieten wirb.

Bertin, aun 1. Mai 1863.

\title{
Dielik. \$cinriøs.
}

\section{$\mathfrak{B} \mathfrak{o} \mathfrak{l} \mathfrak{r} \mathfrak{e} \mathfrak{d} \mathfrak{e}$

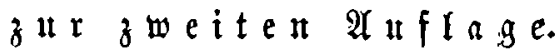

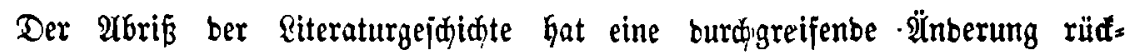
fidtlth) ber Daritellung bejonbers burch Rürzung ber jut ausgebefinten Säkę,

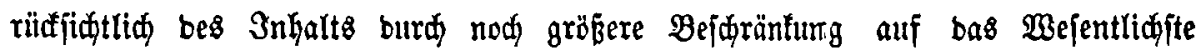

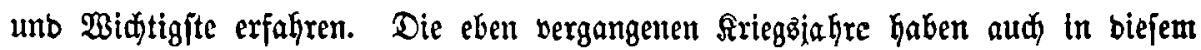
Saanbbuthe bie ifnen gebührente Berüffichtigung burd Scinjufügung mehrerer auf

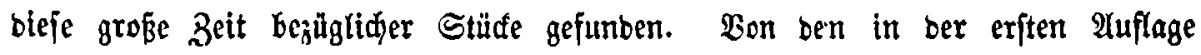
entf̧altenen Mufteritüfen jint aus verffiebenen Grünben einige fortgeblieben.

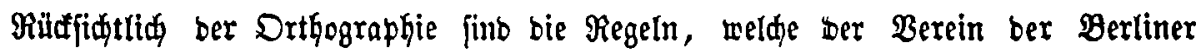


(Squmafial = umb Realiqulleḩrer (Berlin 1871) aufgeftellt hat, möglidjit lonjequent

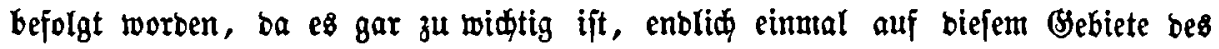
beutiden unterridts eine Einigung ber Rehrer wenigftens ben Schülern gegenüber herbeizufübren. Wenn hier unb ba nod cinige Átweidungen unb 3ntonjequenzen beim Dructe fteben geblieben finb, fo molfe man biejelben gütigit entfdulbigen, ba sie Durdfführung ber neuen Sdreibweije sur屯 bie Beläufigfeit ber Gertömmliden no屯

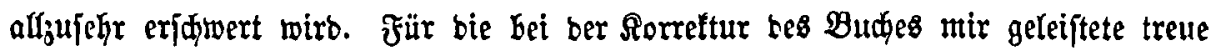
Şülfe jage id bem Şerrn Dr. F. Bajebow Gerzlidfiten Danf.

Berlin, am 30. 3uri 1872.

\section{\$eintiđs.}

